\title{
Necrotizing Enterocolitis: Case Report with Bibliographic Review
}

\section{Cely Carolyne Pontes Morcerf ${ }^{1 *}$, Bruna Alves Cambraia ${ }^{1}$, Fabiana Cerqueira Abbud ${ }^{1}$ and Lucila Bragantini Prata ${ }^{2}$}

${ }^{1}$ Department of Medicine, Universidade do Grande Rio, Rio de Janeiro, Brazil

${ }^{2}$ Department of Neonatology, Universidade do Grande Rio, Rio de Janeiro, Brazil

${ }^{*}$ Corresponding author: Cely Carolyne Pontes Morcerf, Department of Medicine, Universidade do Grande Rio, Rio de Janeiro, Brazil, Tel: 55(21)98168181; E-mail: cely_carol@hotmail.com

Received date: May 4, 2018; Accepted date: May 24, 2018; Published date: May 31, 2018

Citation: Pontes Morcerf CC, Alves Cambraia B, Cerqueira Abbud F, Bragantini Prata L (2018) Necrotizing Enterocolitis: Case Report with Bibliographic Review. Pediatric Infect Dis Vol.3, No.2: 7.

Copyright: C2018 Pontes Morcerf CC, et al. This is an open-access article distributed under the terms of the Creative Commons Attribution License, which permits unrestricted use, distribution, and reproduction in any medium, provided the original author and source are credited.

\begin{abstract}
Necrotizing enterocolitis (NEC) is the clinical and surgical emergency most frequently found in neonatology with a mortality rate of approximately $50 \%$ in newborns weighing less than 1,500 grams. Corresponds to a variety degrees of ischemic necrosis of the newborn's large and small intestines. It has a poorly defined, complex and multifactorial etiology, and it's most commonly found in premature infants. Infectious agents, hypoxia and ischemia have an important role in the etiology of the disease with lesions of the intestinal mucosa triggering inflammatory reaction and necrosis, with enteral nutrition being an extremely relevant factor for the contribution of disease development. The treatment of necrotizing enterocolitis is essentially clinical, but a surgical approach can be performed in some cases of complications, as pneumoperitoneum, fixed intestinal loop on radiological examination and decline in the child's clinical general state. The present paper reports the case of a preterm newborn who developed necrotizing enterocolitis and aims to conduct a discussion associated with dialogues using the current scientific literature regarding the clinical, diagnostic and better management for the case, as well as risk factors and complications.
\end{abstract}

Keywords: Necrotizing enterocolitis; Neonatology; Prematurity

\section{Introduction}

Necrotizing enterocolitis (NEC) is characterized by a gastrointestinal inflammatory disorder, predominantly affecting preterm and low birth weight infants, which manifests itself exaggerated and severe in an environment of intestinal immaturity, thus increasing the risk of pathogenic bacterial invasion $[1,2]$. This pathology extends in the most severe cases to a clinicopathological syndrome of systemic signs and symptoms of variable and progressive intensity, consequent to the necrosis of coagulation of the gastrointestinal tract $[3,4]$.
Due to its high degree of involvement, it has been considered the most common clinical/surgical emergency acquired in the neonatal period, being the major cause of morbidity and mortality of newborns in NICU worldwide [1,5-9]. Morbidity and mortality are inversely related to weight and gestational age at birth, being more exacerbated in newborns between 500 and $1500 \mathrm{~g}$ and in those that require surgeries. It occurs in $1-5 \%$ of all neonatal intensive care hospitalizations and $5-10 \%$ of very low birth weight infants [10].

The pathogenesis is complex and multifactorial. The three main factors responsible are bacterial colonization of the intestine, formula feeding and prematurity, the latter being the most important [11,12]. It is attributed to the degree of intestinal immaturity related to the motor and digestive functions, integrity and function of local mucosal defense, regulation of inflammatory gastrointestinal response, hemodynamic responses of the splanchnic and systemic circulations, associated to the presence of the substrate in the lumen of the intestine and modification in the intestinal colonization pattern $[12,13]$.

In clinical manifestations, abdominal distension and/or pain, nausea, vomiting, difficulty in gastric emptying and fecal alterations such as hematochezia, systemic signs and symptoms such as apnea, bradycardia, lethargy and thermal variations until the onset of fulminant systemic collapses such as apnea respiratory failure and cardiovascular and hemodynamic collapse $[1,3,7,8]$.

Protective measures include administration of prenatal cortico- therapy enteral administration of probiotics in neonates with risk factors for NEC, use of enteral antibiotic therapy, administration of supervised parenteral diet, minimum enteral institution, enteral feeding with human milk, enteral administration of IgG and IgA immunoglobulins [1,2,9,14-17].

The main complications following NEC are the development of short bowel syndrome, intestinal stenosis, need for colostomy, and difficulty in reestablishing the early enteral diet $[5,7,18,19]$.

The diagnosis is often made at the stage of progression of the pathology, in which there is presence of blood in the stool, 
abdominal distension, vomiting or gastric stasis, accompanied by radiological and laboratory signs in the most severe cases. is the standard gold standard for the diagnosis, follow-up and detection of complications $[18,20]$.

Treatment depends on the degree of involvement of the gastrointestinal tract and the severity of the presentation of the disease. Among the main therapeutic measures are enteric isolation, antibiotic therapy, nasogastric tube for decompression of the abdomen and minimal enteral diet associated with parenteral. In the most severe cases there may be a need for surgical intervention $[4,5,7,14]$.

\section{Materials and Methods}

\section{Review and clinical examination}

This is a descriptive study of the Case Report of a preterm newborn who evolved after a few days of life with necrotizing enterocolitis, using retrospective information, as well as followup and care. The data for the report were collected by consulting the patient's chart at the Leila Diniz Maternity Hospital, in the city of Rio de Janeiro, and the findings were confronted with the literature. Photographs of patient imaging were also obtained for the construction of the present study.

\section{Bibliographic research}

Subsequently a bibliographic research was also carried out in the Virtual Library in (VHL), using the descriptors in Portuguese and English "necrotizing enterocolitis" and "necrotizing enterocolitis", obtaining a result of 2,895 articles. Only articles of English and Portuguese language were filtered from 2001 to 2015, resulting in a final balance of 1,796 articles, of which 46 were selected for the present study.

\section{Inclusion and exclusion criteria}

They were selected based on their relevance, relevance, publication in known and reliable journals. The articles that did not present adequate methodology or did not address the area of interest were discarded after reading.

\section{Ethical aspects}

Free and Informed Consent Form (TCLE) was applied, being the same signed by the person in charge with complete confidence that the information will be kept confidential.

\section{Standards adopted}

This work was carried out according to the norms of the International Committee of Medical Journal Editors (Normas de Vancouver) for the presentation of manuscripts.

\section{Results}

\section{Case report}

Female RN, borned on 05/28/2017 at the Leila Diniz Maternity Hospital, of vaginal delivery for preterm labor (30 weeks by DUM and USG) with placenta $30 \%$ off, apgar $8 / 9$. No need for resuscitation maneuvers and weighing $1500 \mathrm{~g}$.

Mother G2P1A1, bag time routed 30 minutes. Serology VDRL negative, anti HIV negative, HBsAg negative, toxoplasmosis IgG and IgM negative (12/24/2016). Quick test for HIV negative (05/28/2017).

Still in the delivery room, live blood was exited in the airway and gastric aspiration of the newborn, and the same, evolved with early respiratory discomfort, being referred to the neonatal ICU for respiratory and nutritional support.

He was admitted to the ICU on the same day of birth with zero diet, requested abdominal $\mathrm{X}$-ray and thorax, non-invasive ventilation, arterial blood gas analysis, blood culture and prescribed Ampicillin+gentamicin. Outcome of gasometry: 7.23/ $\mathrm{PCO}_{2} 49.3 / \mathrm{pO}_{2} / 88.4 / \mathrm{Be}-6.4 / \mathrm{HCO}_{3} 21.2 /$ Saturation $94.8 \%$. Hemoculture negative.

During this period, $\mathrm{RN}$ remained stable with $\mathrm{BEG}$, stained, hydrated, eupneic in NIV. Respiratory apparatus with universally audible vesicular murmur, without adventitious noise. Cardiovascular system with regular 2-stroke heart rate, normal heart sounds, no heart murmurs, heart rate of $118 \mathrm{bpm}$. Globular abdomen, peristaltic, without visceromegalias. The diet became oral human milk.

At the $10^{\text {th }}$ day of life, $\mathrm{RN}$ presented hypoactive, reactive to the manipulation, with important abdominal distension and bloody stools. An X-ray of the abdomen was requested where he found a small sheet of free gas in the cavity. He initiated tazocim, fentanyl and diet zero, with $\mathrm{HV}$ and parenteral nutrition, suspecting NEC.

On the $13^{\text {th }}$ day of life, blood culture evidenced positive ESBL Klebsiella pneumoniae, and meropenem exchange of tazocim was performed and rigorous observation was maintained. On the same day, RN evolved with saturation drop of up to $85 \%$ with bradycardia and hypotonia, orotracheal intubation was performed with orotracheal tube number 3. An X-ray was performed with a pulmonary expansion report reduced by abdominal distension.

At the examination after TOT, RN was active, reactive, hypoxic $1+/ 4+$, acyanotic, anicteric with good peripheral perfusion, saturating $100 \%$ in IMV $20 \times 5 \times 30 \times 21 \%$. Distended abdomen, reduced peristalsis and painful palpation. Gasometry: ph: 7.21/ $\mathrm{pCO}_{2}: 54.4 / \mathrm{pO}_{2}$ : 68.1/Bic: $22.4 / \mathrm{BE}:-5.6 / 99 \%$.

On the $14^{\text {th }}$ day of life, still on zero diet, parenteral nutrition, venous hydration, meropenem $40 \mathrm{mg} / \mathrm{kg} / 12 / 12 \mathrm{~h}$ dose, NB presented a severe but stable picture. It had minimal activity, hyporreative, hypocorate, hydrated, acyanotic, good peripheral perfusion. Abdomen still distended, difficult to palpate, peristalse well reduced. 
In the $15^{\text {th }}$ was performed X-ray with the report of "gas poverty with evolutionary improvement".

In the $19^{\circ}$ hipoactive but reactive NB, hypoxic 1+/4+, hydrated, anicyric, acyanotic. Respiratory system: universally audible bladder murmur with snoring. FR: $51 \mathrm{pmpm}$ in IMV (20/5/20/30\%). Sat 97\%. Acv: no changes. Abdomen globose, depressible, painless, without masses or visceromegalias and peristalsis present. Repeated X-ray with better evolutionary abdomen.

At $23^{\circ}$, after 10 days of $\mathrm{VMI}$, was extubated to ambient air, Sat: $92 \%$, performed nebulization with adrenaline and suspended fentanyl, started LHO diet, with gradual reduction of parenteral diet. On the $27^{\text {th }}$ day of life, meropenem was suspended after 14 days of use. On the $31^{\text {st }}$ day of life there was suspension of parenteral nutrition and diet with human milk.

Still in kangaroo D1, he had 1 episode of feces with blood streaks. As abdomen was innocent at the time it was chosen to start diet excluding milk protein to mother and maintain exclusive breastfeeding. On the $33^{\text {rd }}$ day of life, (D2 kangaroo): presented weight drop, weighing 2065 grams.

On the $34^{\text {th }}$ day of life, he presented a new episode of feces with streaks of blood. The mother was advised to maintain a restricted diet + regular supplementation after the mother's breast, since NB presented progressive weight loss.

For 10 days the neonate remained hospitalized, clinically stable, without new episodes of feces with streaks of blood. In maternal breast+complement. Mother stayed on restricted diet. He presented nutritional recovery and received discharge from the kangaroo with 44 days of life, weighing $2.095 \mathrm{~g}$, for outpatient follow-up.

\section{Bibliographical Review}

\section{Risk factors for necrotizing enterocolitis}

In spite of the great number of current advances in the treatment of necrotizing enterocolitis and in neonatology in general, the disease still stands out due to the high morbidity and mortality among premature infants, being one of the main ones in this specific population. Thus, it is necessary at first to look for the main risk factors that contribute to the development of pathology [1,21-23].

The literature highlights prematurity as being the most relevant risk factor in necrotizing enterocolitis, marking an inverse proportion of incidence of the disease to birth weight and gestational age. The disease occurs in approximately $5 \%$ of preterm infants with a gestational age of less than 32 weeks or a birth weight of less than 1,500 g and in $10 \%$ of preterm infants with gestational age less than 28 weeks or with a birth weight of less than $1,000 \mathrm{~g}[21,23]$.

Other factors may also predispose to the disease, such as rupture of the pouch for more than $36 \mathrm{hrs}$, perinatal hypoxia, maternal prepartum hemorrhage, hyaline membrane disease, hypothermia, umbilical catheterization, polycythemia hypotension, use of indomethacin, as well as the mother of cocaine [1,21-23].

With regard to full-term newborns, the most serious cases of NEC are associated with high rates of nosocomial infections in neonatal ICUs, inadequate enteral nutrition, intrauterine growth retardation, respiratory conditions that prolong neonates' stay in these places, such as hyaline membrane disease, genetic predisposition and deficits of neurodevelopment $[1,22,23]$.

\section{Clinical manifestations of neonatal necrotizing enterocolitis}

Initially, we can evidence discrete systemic signs such as lethargy, bradycardia, temperature and apnea variations, as well as food intolerance, including vomiting, abdominal pain and distention. There may also be signs of fulminant systemic collapse such as cardiovascular and hemodynamic collapse and severe apnea in the newborn.

One or more of the following clinical signs may be present: fecal changes, hematochezia, palpable mass in the abdomen, abdominal distension, reduction of airway noise, erythema in the abdominal wall and increased abdominal circumference $[1,24,25]$.

\section{Diagnosis}

An analysis of the hemogram of the patient with NEC reveals evidence of infection, and the finding of leukocytosis may indicate an infectious condition, but leucopenia $(<5,000$ leukocytes) is a sign of greater severity of the disease. Moderate neutropenia may also be found, pointing to the development of neonatal sepsis [15].

An acute reduction of the hematocrit in the red series may be observed due to the presence of hematochezia or the development of coagulopathy. Thrombocytopenia may also be found, which is common with or without the presence of disseminated vascular coagulation in the patient with NEC $[7,16]$.

It is important that the collection of blood for blood culture is done before antibiotic therapy in patients with suspected sepsis or NEC, because sepsis can mimic negative blood culture, even if it is not positive in the vast majority of cases [7].

Imaging tests are also essential for the diagnosis of NEC and should be associated with the patient's clinic and laboratory. A simple abdominal $\mathrm{X}$-ray in anteroposterior (AP) and left lateral decubitus incidence is necessary for the initial analysis of any child with signs of necrotizing enterocolitis, being the first line examination for the correct diagnosis. These radiographs can be repeated to follow the evolution of the case in a period of six to eight hours in AP incidence, to left lateral decubitus every 2-3 days and a radiograph in a daily supine position. They may be present as radiographic abnormalities, abdominal wall thickening, dilatation of intestinal loops and an abnormal distribution of intestinal gas [26].

Intestinal pneumatosis, defined as the presence of air in the intestinal wall, is characterized as a pathognomonic radiological 
signal of NEC. However, the most frequent radiological alteration in NEC is the generalized gastric distension of intestinal loops [17].

Once the presence of pneumatosis has been established, serial control with AP radiographs and left lateral decubitus with serial repetitions should be performed, depending on clinical status of the neonate. Such a period may be discontinued of observation after 2 to 3 days if it presents a good general condition since the perforations are more frequent at the beginning of the diagnosis in the first two days or until the pneumatosis disappears according to specific authors of the literature [18].

Aeroportia is a finding that corresponds to fine luscism of the hepatic portal region to the peripheral region of the liver and corresponds to a practically pathognomonic finding of NEC. Other findings that may be present are the presence of portal gas, which is transitory indicating the presence of air in the portal venous system and pneumoperitoneum, with good visibility in left lateral decubitus $[17,18]$.

In cases of early stages of NEC, classic findings such as abdominal distension and intestinal pneumatosis may not be detectable with conventional single radiography, and ultrasonography may be used for early diagnosis. The use of abdominal ultrasonography (USG) is advantageous because it is non-invasive and portable, but it has the issue of being a dependent examiner, and is not always available in all services. Ascites is a late finding because it appears a while after perforation, with peritonitis already in place, and is seen with the use of ultrasonography $[7,26,27]$.

Abdominal USG is superior when compared to radiography to identify the presence of air in the portal system and is very good for quantifying ascites, evaluating the with sequential exams. The USG with color Doppler is more accurate than the abdomen radiograph and clinical examination as predictive of loop necrosis in necrotizing enterocolitis. Studies show that more severe cases of NEC are related to findings in the USG of free peritoneal gas, focal collections of fluid or of three or more of the following: absence of bowel perfusion at Doppler, increased intestinal wall echogenicity, gas at the door, thickening of the intestinal wall (greater than $2.7 \mathrm{~mm}$ ) intestinal wall thinning (less than $1 \mathrm{~mm}$ ), free fluid with echoes and intramural gas. The USG was extremely useful in cases of non-specific and indeterminate clinical and radiological findings for NEC and in cases with a diagnostic definition of necrotising enterocolitis, but without good therapeutic response of the newborn $[17,18,27]$.

The staging of the signs and symptoms of necrotizing enterocolitis is established using the modified Bell criteria, initially described in 1986 in the author's literature, based on the clinical, radiological and laboratorial signs of the patient, useful for orientation therapeutic and prognostic evaluation, being divided in degrees IA and IB when NCD, degrees IIA and IIB were diagnosed, confirmed diagnosis and moderate staging and degrees IIIA and IIIB, confirmed diagnosis and severe staging [21].

\section{Treatment}

The treatment varies according to the degree of intestinal involvement and the severity of the disease. As main therapeutic measures we have the use of antibiotic therapy, use of nasogastric probing for abdominal decompression, enteric isolation and minimal enteral diet associated with parenteral. Enteric isolation is an important measure to be performed in all patients with suspected NEC or confirmation of pathology. The need for surgical intervention may arise in cases of severity. There are absolute indications for surgical treatment of suspected intestinal perforation, presence of pneumoperitoneum, clinical deterioration even in maximal medical treatment, abdominal mass with intestinal obstruction to established abdominal radiography, and no surgeries in unstable or less severe neonates are indicated, thus making such interventions as a poor prognostic factor and the indicative of disease in advanced staging according to the modified Bell criteria.

Regarding the most frequent surgical procedures among newborns with necrotizing enterocolitis, there is variation regarding surgical strategies, indications and evidences, and peritoneal drainage is used by most pediatric surgeons to stabilize the clinical picture and definitive treatment. Primary anastomosis and intestinal resection are influenced by the weight of the newborn and are preferably performed in the newborns with a higher weight. Laparotomy with jejunal deviation and jejunostomy, resection and stomatal performance may also be used [24-27].

One study observed that measurements performed on abdominal radiographs confirm numerically the impression of clinical experiences that distended loops have worse prognoses. Neonates with unfavorable evolution, needing a surgical approach, had complications or who died due to abdominal radiography at the moment of hospitalization, more distended intestinal loops on the abdominal radiograph, suspected of necrotizing enterocolitis. Premature newborns with intestinal distention secondary to ventilatory assistance in positive pressure breathing should be treated with caution, because in these cases this finding does not necessarily represent a serious clinical condition [25].

At the onset of suspicion of necrotizing enterocolitis it is recommended to initiate a parenteral diet in the neonate. Restarting the enteral diet may occur between 10 and 14 days after normalization of abdominal radiography in non-surgical cases of NEC. In the surgical cases of NEC, a delay in the reintroduction of the diet may occur, and it is necessary in some services to perform a contrasting examination of the bowel before the release of the diet for the child [28].

Antimicrobials are widely used in the treatment of sepsis although there is no specific infectious agent for NEC. It is important to establish coverage for Gram-positive and Gramnegative germs, in addition to coverage for anaerobes in children older than one week and showing a radiological progression of NEC. The most commonly used regimen includes vancomycin, cefotaxime and clindamycin or metronidazole. Ensures coverage for Gram-positive, including Staphilococcus, 
good coverage for Gram-negative, but not covering Pseudomonas, and coverage for anaerobic germs. Antimicrobial agents are widely used for the treatment of sepsis even though there is no infectious agent specific for NEC. No specific pathogen is consistently associated with onset pathology, even though there are several factors associated with the development of NEC. However, some bacteria such as Pseudomonas, Salmonella, Escherichia coli, Klebsiella, Enterobacter, Clostridium, Staphylococcus coagulae and Enterococcus, as well as some viral agents were isolated from neonatal blood cultures in occasional outbreaks in health services with preterm and low birth weight [29-31].

Antifungal therapy, where fluconazole may be initiated, should be considered in preterm infants with a history of prolonged or recent use of antibiotics and in babies with clinical and/or haematological worsening even with adequate antimicrobial coverage [29].

In cases of need for surgical intervention, the types of treatment that may be used are peritoneal drainage, intestinal resection and enterostomy, resection and primary intestinal anastomosis, as well as other forms of intestinal segment reevaluation, but with doubtful viability. Among other forms, in cases of need for several resections, conservative surgery can be performed with a new surgery in 24 to $48 \mathrm{hrs}$, allowing a reassessment of segments. High derivative jejunostomy without bowel resection associated with surgical re-exploration in 6 to 8 weeks may also be another option. Finally, there is also the technique of clip and drop back, which allows the resection of areas of necrosis associated with an irrigation and aspiration of contaminated peritoneal contents $[27,30,32,33]$.

\section{Determination of severity and treatment: Bell stages}

The stages created by Bell are currently used in the definition of absence or presence of gravity in the case analyzed. However, the use of the stages does not have validity or adequacy in determining the best moment in which the surgery should be performed as a patient's treatment, but historically they have been widely used in the therapeutic orientation. They are organized into 3 divisions and subclassifications in $A$ and $B$ $[18,27,30,32]$.

Stage I Bell points to a suspected NEC. It is subdivided into Stage IA and IB. In Al, there are non-specific systemic signs of mild intensity, discrete intestinal signs such as a mild abdominal distension and an elevation of the stomach residue. Other findings include bradycardia, apnea and thermal instability. The radiograph may show a small abdominal distension or may not show abnormalities. A zero enteral diet and antibiotic therapy for three days are the established treatment for this phase [29,31-33]

Stage IB encompasses few differences in relation to IA, including findings similar to those of the previous stage to identify bloody stools, with treatment of zero enteral diet and antibiotic therapy for three days $[29,32,33]$.

Bell Stage II comprises the defined ECN. Its IIA stage subdivision comprises systemic findings in stage I, associated with stage I intestinal signs, abdominal discomfort and absence of airborne noises. Intestinal pneumothosis and total intestinal obstruction are findings that may be present in association or alone with radiological examination. For this stage, the treatment consists of zero diet and antibiotic therapy during a period of 7 to 10 days. In stage IIB, the patient is moderately affected by the pathology and the diagnosis encompasses the presence of all signs recorded in stage I, along with moderate systemic signs such as thrombocytopenia and mild metabolic acidosis. At the examination, there is evidence of abdominal pain, which may occur with the appearance of a palpable mass in the lower right quadrant or erythema. The presence of gas in the portal system associated or not with ascites is the classic finding in imaging studies for the stage in question $[29,32,33]$

Bell Stage III shows advanced, severe NEC that has a high chance of needing to intervene surgically after disease progression. The subtype IIIA of this stage corresponds to severe NEC, but with no intestinal damage. The diagnosis encompasses all the conditions already mentioned in previous stages, associated with bradycardia, hypotension, severe metabolic acidosis, coagulopathy, respiratory failure and neutropenia, which may be present or not associated with the previous ones. Significant abdominal distension and signs of generalized peritonitis are also evident. Ascites is evidenced in radiological exams. As treatment for this stage, ventilatory support, fluid administration, inotropic support, zero enteral diet for 14 days and paracentesis are considered [29,32,33].

Stage IIIB includes very severe cases with intestinal perforation, and the presence of free air in the abdominal cavity is indicative of surgical treatment. Surgery includes resection of the affected portion of the intestine, and an ileostomy is performed with subsequent closure at another time. When it is a case in which the child is very small or because of a clinical instability, making a laparotomy unfeasible, but there is the presence of free air inside the abdominal cavity, the initial use of peritoneal drainage until the child acquires surgical conditions should be considered. Intestinal perforation and presence of pneumoperitoneum are the only absolute surgical indications, usually observed with abdominal radiography [29,32-34].

\section{Possible complications}

They contribute to the appearance of possible complications after the surgery, the immaturity of the immunological and metabolic function of the neonates, reduced tissue strength, and inadequate reserves. Anastomosis, wall dehiscence and stoma prolapse are complications associated with tissue integrity and have a small impact on the evolution of the condition, and treatment in these cases is simpler. Severe hepatic hemorrhage, with or without obvious iatrogenic injury during exploratory laparotomy, has frequently been reported as a complication in neonates with preoperative hypotension. The newborn's liver may present with significant bleeding, since it is fragile and may bleed from any lesion in Glisson's capsule [33-35].

Intestinal stenosis is a very common late complication and occurs in up to $30 \%$ of cases surgical treatment and up to $36 \%$ of cases with clinical treatises, being the most frequent place of stenosis in thin the region of the terminal ileum and left colon. A range of $9 \%$ to $25 \%$ develops with short bowel syndrome $(\mathrm{SCI})$, a 
consequence of the resection of necrotic segments and residual or remaining bowel motility of the remaining intestine after resolution of acute enterocolitis [35-37].

\section{Discussion}

In the present case, we observed prematurity as a determining factor for the evolution of the NEC present in the newborn. Regarding the characteristics of the newborn, preterm birth and low birth weight are considered risk factors for necrotizing enterocolitis, with infants with a borderline weight corresponding to a higher chance of developing NEC when considering less than $1500 \mathrm{~g}$ at birth, but some studies reduce this number in relation to weight to $1000 \mathrm{~g}$. According to the literature, premature newborns may develop NEC within a few weeks after birth, as the age of onset is inversely proportional to the gestational age at birth

During the evolution of the case, we observed that the neonate shows signs well described in the scientific literature as characteristic of necrotizing enterocolitis, such as the presence of bloody stools, respiratory discomfort, need for orotracheal intubation, invasive mechanical ventilation, abdominal distension and abdominal pain [38-40]. He also presented a radiological signal corresponding to the presence of a free gas slide in the abdominal cavity.

Radiological studies of the abdomen are extremely important, not only for the initial diagnosis of NEC, but also for monitoring the progression of the disease, evaluating the results of the tests and treatment. Abdominal radiographs should be performed at intervals of six to eight hours, within the first $72 \mathrm{hrs}$ after the onset of the disease clinic, and thereafter every 12 to $24 \mathrm{hrs}$, taking into account the patient's evolution, with the clinical case in question correctly conducted according to the specifications of the literature, from the suspicion of NEC to the discharge of the child from the kangaroo ward for outpatient follow-up $[7,22,27,32]$.

When comparing the points of the treatment performed with what is present in the literature, we can classify the RN as being in the stage of Bell IIA, with the presence of systemic manifestations, radiological signs, presence of abdominal discomfort, bloody stools, thrombocytopenia, defined treatment consists of zero diet and antibiotic therapy for a period of 7 to 10 days, not requiring surgical intervention, since oneonato evolved clinically and radiologically well after a few days in the kangaroo ward. The patient in question did not evolve with any complications for NEC described in the literature.

When presenting weight loss during hospitalization, the maintenance of a restricted diet associated with a regular complement after the maternal breast was performed, resulting in a later evolution with nutritional recovery. Many studies report that breast milk is a protective factor and preterm newborns who are exclusively formula fed have a much greater risk for the disease than those fed by human milk. Some authors have described in the literature the fact that NEC presents more mildly in newborns breastfed. Breast milk in natura has a higher protein content than pasteurized milk and keeps anti-infective and immunological factors providing protection. In the case in question, the diet with human milk was started on the $23^{\text {rd }}$ day of life, with a reduction of the parenteral diet in a gradual manner.

There is no specific pathogen defined in the literature as associated with the onset of NEC in a patient, but bacteria such as Pseudomonas, Salmonella, Escherichia coli and Klebsiella were isolated from blood cultures of newborns and cited in many studies that analyzed outbreak cases in health services of preterm newborns. In the clinical case in question, blood culture showed Klebsiella pneumoniae ESBL positive, with the introduction of meropenem, in addition to the strict observation of the newborn.

About $75 \%$ of patients with NEC will survive, according to recent studies and of these, $50 \%$ even develop chronic complications, the two most common being intestinal stenosis and short bowel syndrome, which was not the patient's case , which evolved well with a clinical and radiological improvement, with discharge from the kangaroo ward and outpatient followup to the case [41-43].

The patient was followed up on an outpatient clinic after being discharged from the kangaroo ward. This factor is extremely important for the observation and control of possible complications or developmental disorders that may appear or factors that lead to an unfavorable evolution of the condition.

\section{Final Considerations}

According to the analysis of the clinical case and the discussion carried out, in a comparative way taking into consideration the behaviors and the evolution of the newborn, we can conclude that the patient was conducted correctly and according to what is most current in the literature. It is essential to note that the child who develops necrotizing enterocolitis (NEC) needs more specific observation and care, with regular multidisciplinary multidisciplinary follow-up, thus avoiding the development of complications and an unfavorable outcome to the child [44-46].

Rapid identification, intervention and correct approach to the newborn are necessary, since the delay in diagnosis and correct intervention in the case of NEC can aggravate the condition, leading to a worse prognosis of the child.

Necrotizing enterocolitis (NEC) is therefore still considered a major challenge within neonatology, requiring a careful diagnosis and follow-up. The diagnosis of the disease in some cases is confusing, requiring the use of more specific exams, but the best and most frequently used examination for diagnosis and follow-up is radiological. It is essential to develop a research and assistance to the newborn in order to involve the entire team, focusing on the treatment and management of the patient.

\section{References}

1. Maheshwari A, Corbin LL, Schelonka RL (2011) Neonatal necrotizing enterocolitis. Res Rep Neonatology 1: 39-53. 
2. Chu A, Hageman JR, Caplan MS (2013) Necrotizing Enterocolitis: predictive Markers and Preventive Strategies. N Reviews 14: 113-120.

3. Miyaki M, Steil F, Sarquis AL, Silva R (2007) Apresentação clínica da Enterocolite Necrosante: diagnóstico e prognóstico. Pediatr 29: 192-199.

4. Miyaki M, Steil F, Sarquis AL, Silva R (2007) Enterocolite necrosante em serviço com banco de leite humano. Pediatr 29: 183-191.

5. Garg P (2007) Necrotising Enterocolitis: newer Insights. J Clin Diagn Res 1: 90-103.

6. Oliveira ND, Miyoshi MH (2005) Avanços em Enterocolite Necrosante. J Pediatr 81: 16-22.

7. Neves LAT, Mendes E, Neves DB (2009) Enterocolite necrozante: um desafio para o recém-nascido prematuro de muito baixo peso. Rev Med Minas Gerais 19: 51-57.

8. Neu J, Walker AW (2011) Necrotizing Enterocolitis. N Engl J Med 364: 255-264.

9. Bell EF (2005) Preventing Necrotizing Enterocolitis: What Works and How Safe? Pediatr 115: 173-174.

10. Thompson AM, Bizzarro MJ (2008) Necrotizing Enterocolitis in Newborns. Drugs 68: 1227-1238.

11. Anand RJ, Leaphart CL, Mollen KP, Hackam DJ (2007) The Role Of The Intestinal Barrier In The Pathogenesis of Necrotizing Enterocolitis. Shock 27: 124-133.

12. Lin PW, Nasr TR, Stoll BJ (2008) Necrotizing enterocolitis: recent scientific advances in pathophysiology and prevention. Semin Perinatol 32: 70-82.

13. Martin CR, Walker WA (2006) Intestinal immune defences and the inflammatory response in necrotizing enterocolitis. Semin Fetal Neonatal Med 11: 369-77.

14. Bueno MB, Reis VS (2011) A importância do leite materno na prevenção da enterocolite necrosante entre recém nascidos. Nutrire Rev Soc Bras Alim Nutri 36: 266.

15. Kling PS, Hutter JJ (2003) Hematologic abnormalities in severe neonatal necrotizing enterocolitis: 25 years later. J Perinatol 23: 523-530.

16. Ververidis M, Kiely EM, Sptiz L, Drake DP, Eaton S, et al. (2001) The clinical significance of thrombocytopenia in neonates with necrotizing enterocolitis. J Pediatr Surg 36: 799-803.

17. Alvares BR, Martins DL, Roma RL, Pereira IMR (2007) Aspectos radiológicos relevantes no diagnóstico da enterocolite necrosante e suas complicações. Radiol Bras 40: 127-130.

18. Souza JCK (2008) Influência da localização da Enterocolite Necrosante na Mortalidade de Recém Nascidos Submetidos à Laparotomia. (Tese de Doutorado). Porto Alegre: UFRGS.

19. Jesse N, Neu J (2006) Necrotizing Enterocolitis: Relationship to Innate Immunity, Clinical Features, and Strategies for Prevention. Neoreviews 7: 143-150.

20. Silva DCB, Quinello C, Pires DA, Pinto JR, Mattar AC, et al. (2008) Uso de fatores de crescimento epidérmico e estimulador de colônias de granulócitos na prevenção e tratamento da enterocolite necrosante no recém-nascido. Rev Paul Pediatr 26: 170-175.

21. Lima SS, Souza JIC, Ávila PES (2015) Enterocolite Necrosante em Unidade de Terapia Intensiva Neonatal. Rev Paraense de Medicina 29: 63-68
22. Schanler RJ (2015) In time: human Milk is the feeding strategy to prevent necrotizing enterocolitis. Rev Paul Pediatr 33: 131-133.

23. Vieira AA, David BBL, Lino RRG, Duarte LB, Bueno AC (2013) Avaliação dos fatores perinatais que interferem na incidência de enterocolite necrosante em recém-nascidos de muito baixo peso. Rev Bras Ginecol Obstet 35: 363-367.

24. Braga TD, Silva GAP, Lira PIC, Lima MC (2012) Enterocolite necrosante em recém-nascidos de muito baixo peso em uma unidade neonatal de alto risco do Nordeste do Brasil (2003-2007). Rev Bras Saúde Matern Infant 12: 127-133.

25. Rocha AA, Silva PSG (2011) Intervenção cirúrgica e fatores associados em neonatos com enterocolite necrosante. Rev AMRIGS 55: 361-364.

26. Miranda FC, Sameshima YT, Deutsch AD, Warth AN, Neto MJF, et al. (2009) Enterocolite necrosante em Unidade de Terapia Intensiva Neonatal. Einstein 7: 91-95.

27. Martins DL, Gonçalves A, Dabus GC, Bustorff-Silva JM, Olímpio HO, et al. (2007) Valor preditivo da distensão de alças intestinais em radiografias no prognóstico de enterocolite necrosante. Radiol bras 40: 297-301.

28. Lin PW, Stoll BJ (2006) Necrotising enterocolitis. Lancet 368: 1271-1283.

29. Froes JHB (2011) Enterocolite necrosante neonatal: revisão de literatura e relato de caso. (Trabalho de Conclusão de Curso). São Paulo: HSPM.

30. Gane B, Bhat BV, Adhisivam B, Joy R, Prasadkumar P, et al. (2014) Risk factors and outcome in neonatal necrotizing enterocolitis. Indian J Pediatr 81: 425-428.

31. Dittmar E, Beyer P, Fischer D, Schäfer V, Schoepe H, et al. (2008) Necrotizing enterocolitis of the neonate with Clostridium perfringens: diagnosis, clinical course and role of alpha toxin. Eur J Pediatr 167: 891-195.

32. Buna CMSC (2015) Análise hierarquizada dos fatores associados à enterocolite necrosante em recém-nascidos de baixo peso. (Tese de Mestrado). São Luiz: Universidade Federal do Maranhão.

33. Gordon PV, Swanson JR, Attridge JT, Clark R (2007) Emerging trends in acquired neonatal intestinal disease: is it time to abandon Bell's criteria? J Perinatol 27: 661-671.

34. Tannuri U, Gomes VA, Troster EJ (2004) Concomitant involvement of the small intestine and the distal esophagus in na infant with massive necrotizing enterocolitis. Rev Hosp Clin 59: 131-134.

35. Moss I, Dimmitt RA, Bamhart DC, Sylvester KG, Brown RL, et al. (2006) Laparotomy versus peritoneal drainage for necrotizing enterocolitis and perforation. N Engl J Med 354: 2225-22234.

36. Petty JK, Ziegler MM (2005) Operative strategies for necrotizing enterocolitis: the prevention and treatment of short-bowel syndrome. Semin Pediatr Surg 14: 191-198.

37. Silva CT, Daneman A, Navarro OM, Moore AM, Moineddin R, et al. (2007) Correlation of sonographic findings and outcome in necrotizing enterocolitis. Pediatr Radiol 37: 274-282.

38. Penha $D$, Rosado E, Paixão $P$, João $P$, Cabral $P$, et al. (2013) Enterocolite Necrosante Neonatal: uma revisão iconográfica das alterações radiológicas. Rev Clin Hosp Prof Dr Fernando Fonseca 2: 34-36.

39. Vieira MTC, Lopes JMA (2003) Fatores associados à enterocolite necrosante. J Pediatr 79: 159-164. 
40. Machado IN, Olímpio H, Barini R, Sbragia L (2007) Efeito da corticoterapia pré-natal na evolução de recém nascidos com enterocolite necrosante. Einstein 5: 252-254.

41. Sigalet DL (2001) Short bowel syndrome in infants and children: an overview. Semin Pediatr Surg 10: 49-55.

42. Nadler EP, Upperman JS, Ford HR (2001) Controversies in the management of necrotizing enterocolitis. Surg Infect 2: 113-120.

43. Henry MCW, Moss RL (2005) Surgical Therapy for necrotizing enterocolitis: bringing evidence to the bedsid. Sem Pediatr Surg 14: 181-190.
44. Piccoli A, Soares CRS, Costa G, Silveira JL, Fiatt MP, et al. (2012) Perfil clínico de neonatos de muito baixo peso internados em uma Unidade de Tratamento Intensivo Neonatal. Rev HCPA \& Fac Med Univ Fed Rio Gd do Sul 32: 412-419.

45. Epelman M, Daneman A, Navarro OM, Morag I, Moore AM, et al. (2007) Necrotizing enterocolitis: review of state-of-the-art imaging findings with pathologic correlation. Radiographics 27: 285-305.

46. Bernardo WM, Aires FT, Carneiro RM, Sá FP, Rullo VEV, et al. (2013) Eficácia dos probióticos na profilaxia de enterocolite necrosante em recém-nascidos prematuros: revisão sistemática e meta-análise. J Pediatr 89: 18-24. 